\title{
Are Land Use Policies Preserving Farmland from Urban Sprawl?
}

\author{
Patricia Abelairas-Etxebarria ${ }^{1} \&$ Inma Astorkiza ${ }^{1}$ \\ ${ }^{1}$ Department of Applied Economics V, University of the Basque Country (UPV-EHU), Bilbao, Spain \\ Correspondence: Patricia Abelairas-Etxebarria, Department of Applied Economics V, University of the Basque \\ Country (UPV-EHU) Av. Lehendakari Agirre, 8348015 - BILBAO, Spain. Tel: 34-94-601-3803. E-mail: \\ patricia.abelairas@ehu.es
}

Received: July 18, $2012 \quad$ Accepted: September 15, $2012 \quad$ Online Published: September 28, 2012
doi:10.5539/res.v4n5p24
URL: http://dx.doi.org/10.5539/res.v4n5p24

\begin{abstract}
The principal objective of this paper is to analyse if land use policies are preserving farmland from urban sprawl. Furthermore, it is analysed if a protected area, with more restricted land use legislation, is more protected from urban sprawl that an area with more flexible legislation. Using an Exploratory Spatial Data Analysis, it is showed that urban sprawl is causing distortions in the desirable uses of both areas and that land use policies are not preserving them from residential uses. A revision of the land use control policies is needed to avoid the loss of their exceptional values.
\end{abstract}

Keywords: urban sprawl, farmland price, land use policy, protected natural area

\section{Introduction}

The high price of urban land represents an important problem in the current land market as it is the main factor responsible for elevated housing prices in cities. These high housing prices, together with the high desirability of the countryside as a place of residence, are leading towards an important demand of periurban land. This phenomenon is called "urban sprawl" and it is becoming usual in areas near cities. From the other side of the market, farmland supply in rural municipalities is controlled by policies because the governments, in general, try to protect the values of our environment. Many authors have studied the phenomenon of "urban sprawl". It is seen as the inefficient land use patterns associated with urban growth and development in rural areas (Olson and Lyson, 1999). These no efficient land uses, which bring the increase in population, are causing an important decrease or farmland in many areas (Nelson, 1999). In the other hand, land use legislation tries to preserve farmland from urban sprawl, due to the fact that it is accepted that urban sprawl has important negative consequences as the damages made in the environment, the rural community and the agrarian activities (Furuseth, 1987; Daniels \& Bowers, 1997; Mariola, 2005).

This paper have two hypothesis: 1) Land use policies are not preserving from urban sprawl land qualified as 'rustic', which is not able to be developed. 2) A protected area, with more restricted land use legislation, is more preserved from urban sprawl that an area with more flexible legislation. The analysis of the legislation and the transactions of plots of rustic land both inside the Urdaibai Reserve (RBU) and round some of its various bordering municipalities in Bizkaia, but under less strict legislation, tries to achieve the objective of contrasting those hypothesis.

The Urdaibai Biosphere Reserve has unique features such as its exceptional natural characteristics and its location only 30 minutes away by car from Bilbao area (Biscay province). Besides, the declaration of Biosphere Reserve by the UNESCO (1984) meant the legislation tried to zealously protect the activities carried out on this rustic land. A bordering area of the reserve, five municipalities which are closer to Bilbao, has been taken as a reference from the non protected area. This area has a strong rural character and high environmental and landscape quality and it is well linked with the city.

The legislation of Urdabai provides a special legal regime to protect the ecosystem. This protection is linked to maintaining existing farming activities. With the aim of regulating land use and authorized construction acts, the law subdivides the rural land in different categories according to their physical and ecological characteristics (Note 1). In two of them, Area of Agricultural Interest and Common Rustic Land Area, isolated residential buildings are allowed for farmers subject to a series of features of the minimum farming unit (Note 2). In the area outside the reserve, the requirements asked by the minimum farming unit are less demanding (Note 3 ). The 
Area of Rural Neighbourhood Centres (RNC) is the only farmland area to support new construction of dwellings unrelated with farming both inside and outside the protected area (Note 4).

The analysis is based in the affirmation that land prices reflect which are their real or potential uses (Plantinga, 2002), and to analyse these prices, a spatial perspective has been developed. The prices of periurban farmland have been studied by many authors in the past (Capozza \& Helsley, 1989; Cavailhès \& Wavresky, 2003; Livanis, Moss, Breneman \& Nehring, 2006). In recent years, studies of spatial effects have been developed and applied in the real estate market (Cho \& Newman, 2005; Huang, Miller, Sherrick, \& Gómez, 2006; Páez, Takashi, \& Kazuaki, 2001; Patton \& McErlean, 2003; Overmars, de Koning, \& Veldkamp, 2003).

Exploratory Spatial Data Analysis (ESDA) has been the methodology used. Exploratory Data Analysis has been generalized recently. This technique tries to find patterns of behaviour of the variables of study, setting a hypothesis with the less structure as possible (Tukey, 1977), but Exploratory Data Analysis does not take into account the spatial dimension. Exploratory Spatial Data Analysis (ESDA) is a sub-discipline of the general Exploratory Data Analysis and it is centred on spatial effects (Anselin, 1999). The principal stage of the ESDA is the study of spatial association, both global and local, that is, the existence of a relationship between what happens in a place and what happens in neighbour places. When observed values of a variable in a region or point depend on values of neighbour regions or points, the variable is spatially autocorrelated.

To study this spatial relationship, the most commonly used weight matrix in the context of the land market, is the inverse square distance matrix (Equation 1) because this matrix gives greater weight to nearer plots and lower weight to more distant plots. The results obtained from the use of the inverse square distance matrix in this analysis are presented below, but it was found that the application of the other matrices leads to the same results.

$$
w_{i j}=\frac{1}{d_{i j}^{2}}
$$

\section{Empirical Results}

The present article analyses the appraised prices per $\mathrm{m}^{2}$ of land transactions in the study areas. Some of these land transactions are located in "pure" farmland (Area of Agricultural Interest and the Common Rustic Land Area), where only the agrarian activity and the construction of farms linked to this activity, with the restrictions mentioned above, is permitted, and some of them are inside Rural Neighbourhood Centres, which are the only farmland areas which support new construction of dwellings unrelated with farming.

A database gathering the data of transactions recorded between 1992 and 2003 in the municipalities above mentioned (Note 5) was developed using the spatial econometric package Spacestat 1.91 and Arc View 3.2, a Geographic Information System programme. It is remarkable that prices chosen as the best reflection of real market, are those that banks stipulate as "appraised price", because the "declared price" is a biased variable due to tax avoidance purposes of landowners. Due to the dispersion of the data, we will focus on the behaviour of the price logarithm. A representation of the map of the variable LNPRICE is shown on figure 1.
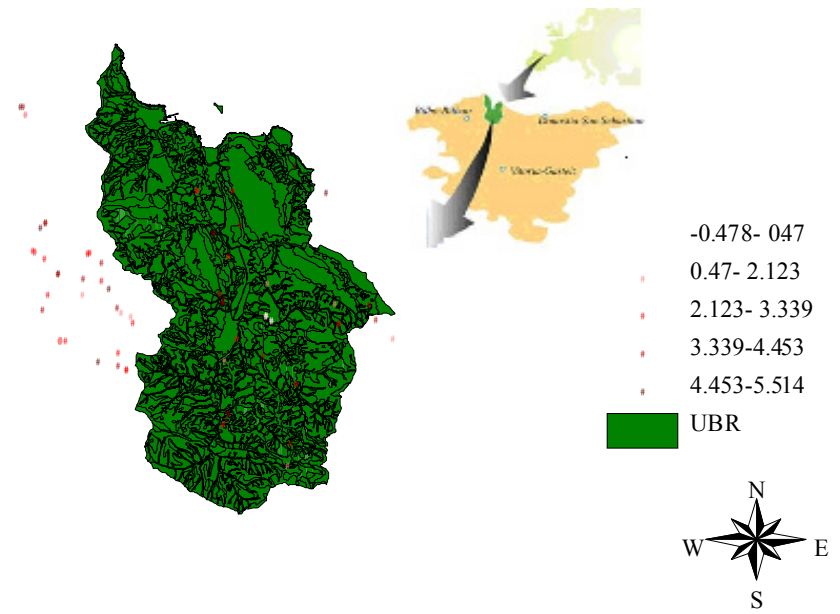

Figure 1. Spatial distribution of the variable lnprice 
The green area of the map represents the Urdaibai Biosphere Reserve and the red points represent the plots of study, some inside the UBR and some outside it. The first trend is the greater presence of dark red colour, representing high prices, both inside and outside the UBR. It is remarkable that we are analyzing prices of rustic land, so prices, in general, were expected to be low due to the low profitability of agrarian activities. Although the characteristics and the legislation of the two areas, UBR and outside the UBR, are different, it seems that the behavior of the prices and, therefore, of the uses of farmland is similar. This denotes that the profit of buying a plot inside a Reserve has been counteracted because the municipalities of the non-protected area are nearer Bilbao.
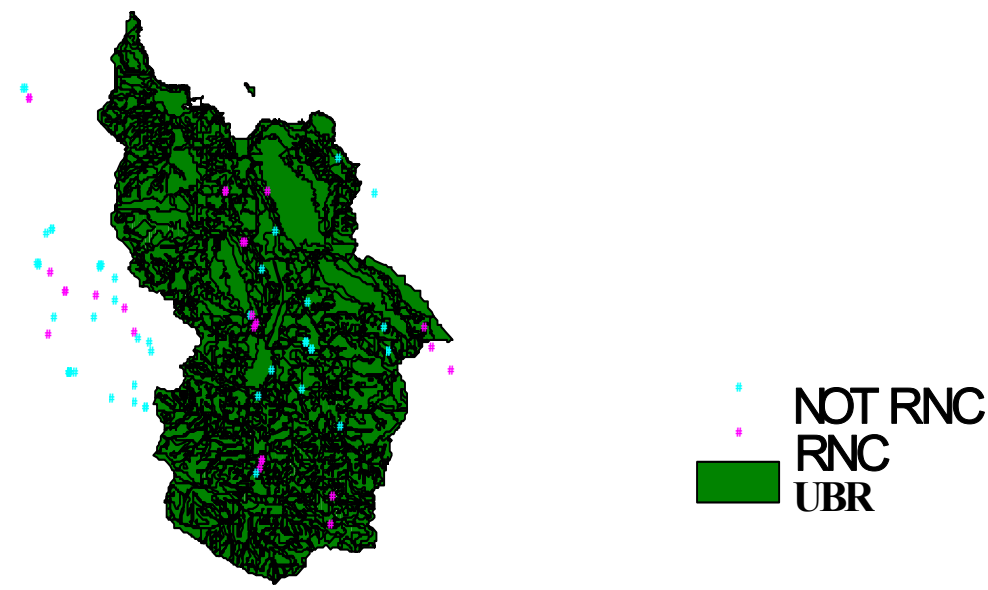

Figure 2. Spatial distribution of the variable RNC

Besides, as we can see comparing Figure 1 and Figure 2, there is no difference between the behavior of plots which are in "pure" rustic land, with agrarian purposes, and the behavior of plots which are inside a Rural Neighborhood Center, with residential purposes. There is another study (Abelairas-Etxebarria \& Astorkiza, 2012) which confirms, with an econometric model, that the variable which collects the location in a Rural Neighborhood Center (RNC), is not significant to explain the prices of rustic land.

Global spatial autocorrelation statistics will now be presented to study whether spatial relationships between neighbour observations exist. The null hypothesis represents the non-existence of spatial autocorrelation and a very significant positive spatial autocorrelation can be inferred from Moran's I and Geary's C on Table 1. In global terms, plots of land lying nearby each other have similar prices. The price of the plots depends on the neighbour plot price ignoring that they have different purposes, some of them must to be used for agrarian activities ("pure" farm land) and some of them must to be used for residential activities (Rural Neighbourhood Centre).

Table 1. Global spatial autocorrelation statistics

\begin{tabular}{lll}
\hline Variable & Moran's I & Geary's C \\
\hline LNPRICE & $6.871707^{*}$ & $-5.459870^{*}$ \\
\hline
\end{tabular}

- * is significant at $1 \%$.

A Moran Scatterplot is presented on Figure 3. This graphic displays the value of the variable of study for a particular observation on the $\mathrm{x}$-axis and the value of the spatial lag variable, i.e. the average value for neighbours of the observation, on the y-axis. 


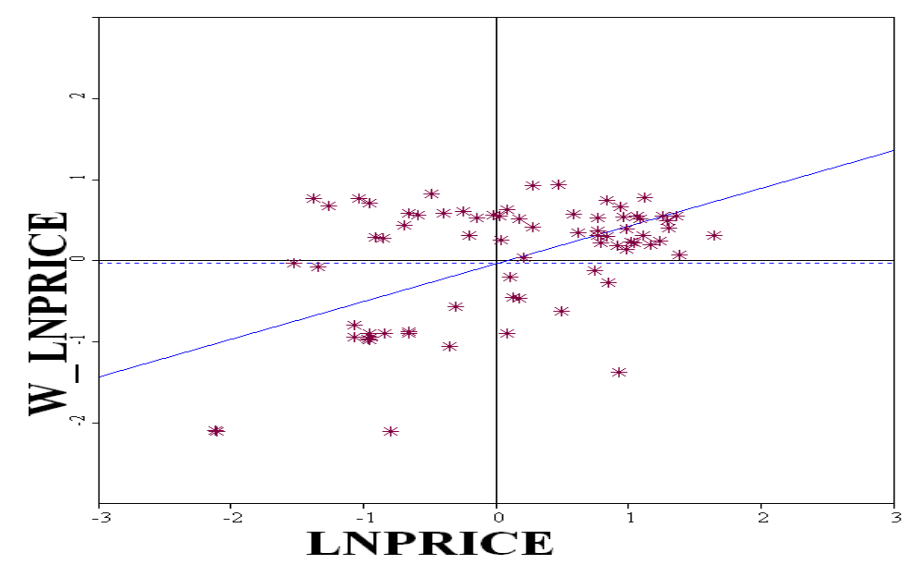

Figure 3. Moran's scatterplot of the variable Inprice (Note 6)

As most of the points are in the first and third quadrant, the Scatterplot supports the positive spatial autocorrelation indicated by the previous statistics. Neighbour plots have similar prices: most of the land with high values is close to high valued plots (first quadrant), and some properties with low prices are neighbours of low valued plots (third quadrant). The first and more frequent case, high prices next to high prices, has to be with residential activities which cause high prices although the vocation of the land could be agrarian. This point is worrying because the residential use of a plot located in "pure" farmland damage seriously the land. The second case, low prices with neighbour low prices, has to be with agrarian activities, but this point is not worrying because the agrarian use of a plot is not at all damaging for the land.

Local Indicators of Spatial Association (LISA) have been calculated but no significant results have been obtained. The low number of observations and the heterogeneity of the database have been a lack to develop this part of the analysis in a right way.

\section{Conclusions and Discussion}

On the one hand, the analysis of two periurban farmland areas, a Natural Protected Area, Urdaibai, and a Natural Area without special protection, has showed that the uses of their farmland are similar, rejecting the hypothesis that a protected area, with more restricted land use legislation, will be more preserved from urban sprawl that an area with more flexible legislation.

On the other hand, we have analysed prices of two types of farmland: "pure" farmland and Rural Neighbourhood Centres. The existence of positive spatial autocorrelation shows that plots of land lying nearby each other have similar prices ignoring the different theoretical activities developed in them. Most neighbour plots have similar high prices which are linked to residential purposes and not to the agrarian ones.

Urdaibai Biosphere Reserve has controlled significantly the residential development but urban sprawl is causing changes in the desirables uses of its farmland. Although the uses of farmlands are, in theory, tightly controlled by land use policies not to damage their exceptional qualities, we have checked that our first and main hypothesis is right. Land use policies are not achieving their objective of preserving farmland from residential activities. Dwellings have been built in "pure" farmland putting forward agricultural purposes, but these agricultural activities are disappearing in a short time.

Given the need to preserve the natural environment and the fact that the residential use of farmland damages seriously the land, we consider that a revision of the land use policies is needed to avoid the loss of their exceptional values. The present policies which try to curb sprawl in this zone, are based in command and control legislation but, as it has been seen in this study, their effectiveness is very limited. These regulations need to be complemented with others with contain low density development and protect the environment, such as Payments for Ecosystem Services, Tradable Planning Permits and fiscal instruments. Firstly, it would be necessary to stop the current tendency of agrarian activities, to liberate funds to finance the competitiveness and growth policies because many ecosystem services are usually considered public goods. Secondly, Tradable Planning Permits can be used to safeguard the open space, agriculture and biodiversity. Third, the welfare loss resulting from the external effects of building on open farmland spaces can be corrected with the taxation of land development by local jurisdictions. 


\section{References}

Abelairas-Etxebarria, P., \& Astorkiza, I. (2012). Farmland prices and land-use changes in periurban protected natural areas. Land Use Policy 29, 674-683. http://dx.doi.org/10.1016/j.landusepol.2011.11.003

Anselin, L. (2005). Exploring spatial data with GeoDa: a workbook. Urbana: Center for Spatially Integrated Social Science.

Anselin. L. (1999). Spatial data analysis with SpaceStat and ArcView. Urbana: Department of Agricultural and Consumer Economics.

Capozza, D. R., \& Helsley, R. W. (1989). The fundamentals of land prices and urban growth. Journal of Urban Economics, 26, 295-306. http://dx.doi.org/10.1016/0094-1190(89)90003-X

Cavailhes, J., \& Wavresky, P. (2003). Urban influences on periurban farmland prices. European review of Agricultural Economics, 30, 333-357. http://dx.doi.org/10.1093/erae/30.3.333

Cho, S., \& Newman, D. H. (2005). Spatial analysis of rural land development. Forest Policy and Economics, 7 , 732-744. http://dx.doi.org/10.1016/j.forpol.2005.03.008

Daniels, T., \& Bowers, D. (1997). Our Ground: Protecting America's Farms and Farmland Island. Press, Washington, D.C.

Furuseth, O. J. (1987). Public attitudes toward local farmland protection programs. Growth and Change, 18, 49-61. http://dx.doi.org/10.1111/j.1468-2257.1987.tb00080.x

Huang, H., Miller, G. Y., Sherrick, B. S., \& Gómez, M. I. (2006). Factors influencing Illinois farmland values. $\begin{array}{lllll}\text { American Journal of Agricultural } & \text { Economics, } & \text { 88, }\end{array}$ http://dx.doi.org/10.1111/j.1467-8276.2006.00871.x

Livanis, G., Moss, C. B., Breneman, V. E., \& Nehring, R. F. (2006). Urban sprawl and farmland prices. $\begin{array}{lllll}\text { American Journal of Agricultural } & \text { Economics, } & 88, & 915-929 .\end{array}$ http://dx.doi.org/10.1111/j.1467-8276.2006.00906.x

Mariola, M. J. (2005). Losing ground: farmland preservation, economic utilitarianism, and the erosion of the agrarian ideal. Agriculture and Human Values, 22, 209-223. http://dx.doi.org/10.1007/s10460-004-8281-1

Nelson, A. C. (1999). Comparing states with and without growth management: analysis based on indicators with policy implications. Land Use Policy, 16, 121-127. http://dx.doi.org/10.1016/S0264-8377(99)00009-5

Olson, R. K., \& Lyson, T. A. (1999). Under the Blade: The Conversion of Agricultural Landscapes. Westview Press, Boulder, CO.

Overmars, K. P., de Koning, G. H. J., \& Veldkamp, A. (2003). Spatial autocorrelation in multi-scale land use models. Ecological Modelling, 164, 257-570. http://dx.doi.org/10.1016/S0304-3800(03)00070-X

Páez, A., Takashi, U., \& Kazuaki, M. (2001). Spatial association and heterogeneity issues in land price models. Urban Studies, 38, 1493-1508. http://dx.doi.org/10.1080/00420980126668

Patton, M., \& McErlean, S. (2003). Spatial effects within the agricultural land market in Northern Ireland. Journal of Agricultural Economics, 54, 35-54. http://dx.doi.org/10.1111/j.1477-9552.2003.tb00047.x

Plantinga, A. J., Lubowski, R., \& Stavins, R. (2002). The effects of potential land development on agricultural land prices. Journal of Urban Economics, 52, 561-581. http://dx.doi.org/10.1016/S0094-1190(02)00503-X

Tukey, J. W. (1977). Exploratory Data Analysis. Addison-Wesley, Reading.

\section{Notes}

Note 1. Special Protection Area, Protection Area, Area of Agricultural Interest, Forest Area, Area of Rural Neighborhood Centres, Common Rustic Land Area and Systems Area.

Note 2. The dwelling must be physically included in a parcel of at least 2.5 ha. and the other plots bound together to the farm must have an additional extension of at least 2.5 ha., but they need not be attached to the house and the farm must occupy at least 1 Annual Work Unit and the farmer must be the head of the farm.

Note 3. The minimum surface of land to build a farmer's house must amount to 1 ha $(0.5$ ha. +0.5 ha. $)$ and it is sufficient to work 0.75 Annual Work Unit in farming/ranching.

Note 4. As provided by the Basque law of land in force throughout the Autonomous Community (region), the increase of new housing in these areas is restricted to twice the existing number when the law was enacted, but 
the total number resulting should not exceed 30 units. The minimum plot size required for building in the RNC depends on the management plans of each municipality and on average is $0.2 \mathrm{ha}$. $(2000 \mathrm{~m} \mathrm{2})$.

Note 5. Provided by the Land Registry of Gernika, by the UBR Trust and by the Cadastre and Valuation Section of the Department of Public Finance of the Biscay Province Council

Note 6. Moran's Scatterplot is done with the K-nearest neighbour matrix (4 neighbours), selected as the more suitable, because GeoDa package (Anselin, 2005) is not able to make it with the inverse square distance matrix yet. 